\title{
SISTEM PERBANDINGAN UNJUK KERJA SIMALARITY SOCAL \& SNEATH II DAN OTSUKA UNTUK PENDETEKSI POLA HURUF MANSHUB FI'IL MUDHARI PADA AL-QURAN
}

\author{
Maryana, Fajriana, Nurdin, Fadlisyah, Aryandi \\ Teknik Informatika Universitas Malikussaleh Lhokseumawe \\ Jl. Cot Tgk Nie-Reulet, Aceh Utara, 141 Indonesia \\ email : aryandi2222@gmail.com
}

\begin{abstract}
ABSTRAK
Pengenalan pola sebuah objek adalah salah satu studi pengenalan pola dalam teori pengolahan citra. Objek yang digunakan untuk studi ini sudah banyak, salah satunya adalah pola citra Alquran yang memuat tentang bermacam hukum Nahwu. Salah satunya adalah hukum Fi' il Mudhari yang mungkin tak asing lagi didengar. Fi'il Mudhari adalah Manshub/dinashabkan sebab dimasuki oleh salah satu Amil dari Amil-amil Nawashib. Pada tugas akhir ini dikembangkan suatu sistem pendeteksian mengenai pembelajaran seputaran pola huruf Fi'il Mudhari tersebut. Sistem ini dibangun dengan menggunakan bahasa pemograman Delphi XE. Proses pendeteksian pola Fi'il Mudhari ini dilakukan dengan menggunakan sebuah metode yang akan menjari nilai jarak (Distance) dari nilai sebuah citra latih dan citra uji Al Quran. Metode digunakan adalah metode Socal \& Sneath II dan Otsuka. Proses sistem pendeteksian ini diawali dengan proses ekstensi file.bmp dari citra asli, kemudian resizing, grayscale, dan konvolusi deteksi tepi. Inputan gambar citra merupakan hasil scanner ayat Al-Quran. Tingkat keakuratan pengenalan pola Fi'il mudhari dalam penelitian ini sangat ditentukan oleh nilai ukur berdasarkan Detection rate setiap pola yang dideteksi..

Katakunci: Al-Quran, Manshub Fi'il mudhari, pengolahan citra, Pengenalan Pola, Socal \& Sneath II, Otsuka.

\section{Pendahuluan}

Al-Quran merupakan pedoman umat Islam dan berisikan firman Allah yang diturunkan kepada nabi Muhammad sebagai penutup para nabi dan rasul dengan perantaraan malaikat Jibril sebagai penyampai wahyu dan ditulis pada mushaf-mushaf yang kemudian disampaikan kepada
\end{abstract}


manusia secara mutawatir, dimulai dari surat Al-Fatihah sebagai pembuka dan surat $\underline{A n-N a s}$ sebagai penutup. Sedangkan dari segi kebahasaan, Al-Qur'an berasal dari bahasa Arab yang berarti "bacaan" atau "sesuatu yang dibaca berulang-ulang" (Muhammad Ali Ash- Shabuni: 2015). Al-Quran juga merupakan kalam Allah yang diturunkan dalam bahasa Arab yang tidak terlepas dari kaidah ilmu nahwu yang terkandung dalam pemberian harkat atau baris dalam Al-Quran. Nahwu adalah kaidah-kaidah Bahasa Arab untuk mengetahui bentuk kata dan keadaan-keadaannya ketika masih satu kata (Mufrod) atau ketika sudah tersusun (Murokkab). Termasuk didalamnya adalah pembahasan shorof. Karena Ilmu Shorof bagian dari Ilmu Nahwu, yang ditekankan kepada pembahasan bentuk kata dan keadaannya ketika mufrodnya.

Dari penjelasan permasalahan di atas, penulis mengembangkan sistem yang menggunakan sistem untuk mendeteksi pola huruf manshub fi'il mudhari di dalam Al-Quran menggunakan penerapan citra (pola). Dengan cara citra surat Al-Quran akan dilatih sebagai input data untuk mendapatkan pola harf (huruf) tersebut. Kemudian akan dideteksi pola yang telah diinput dan dibandingkan dengan citra surat Al-Quran uji.

\section{Metode Penelitian}

\subsection{Metode Socal \& Sneath II Dan Otsuka}

Terdapat dua benda atau pola, i dan j diwakili oleh bentuk vektor biner. Misalkan $\mathrm{n}$ jumlah fitur ( atribut ) atau dimensi vektor. Definisi binary similarity and distance measures dapat di ekspresikan oleh Unit Taksonomi Operasional ( Otus seperti yang ditunjukkan pada Tabel 1 ) dalam tabel kontingensi $2 \times 2$ dimana A adalah sejumlah vektor di mana nilai-nilai i dan $\mathrm{j}$ keduanya 1 ( kecocokan yang positif ), b adalah jumlah atribut di mana nilai i dan $\mathrm{j}$ adalah $(0,1)$, yang berarti $\mathrm{i}$ (ketidak sesuaian vektor), $\mathrm{c}$ adalah jumlah atribut di mana nilai i dan $\mathrm{j}$ adalah ( 1,0$)$, yang berarti $\mathrm{j}$ adanya (ketidak sesuaian vektor), dan $\mathrm{d}$ adalah jumlah atribut di mana kedua i dan j memiliki 0 ( atau tidak adanya kecocokan )

Tabel 2.3. Tabel Otus

\begin{tabular}{|c|c|c|c|}
\hline $\mathrm{i} / \mathrm{j}$ & $\mathrm{I}$ ( presence) & 0 (absence) & sum \\
\hline $\mathrm{I}$ ( presence) & $\mathrm{a}=\mathrm{i} \cdot \mathrm{i}$ & $\mathrm{b}=\mathrm{i} \cdot \mathrm{i}$ & $\mathrm{a}+\mathrm{b}$ \\
\hline 0 (absence) & $\mathrm{c}=\mathrm{i} \cdot \mathrm{j}$ & $\mathrm{d}=\mathrm{i} \cdot \mathrm{j}$ & $\mathrm{c}+\mathrm{d}$ \\
\hline Sum & $\mathrm{a}+\mathrm{c}$ & $\mathrm{b}+\mathrm{d}$ & $\mathrm{n}=\mathrm{a}+\mathrm{b}+\mathrm{c}+\mathrm{d}$ \\
\hline
\end{tabular}


Nilai a diperoleh dari nilai dari vektor $i$ dan $j$ bernilai $(1,1)$ maka artinya vektor tersebut mememiliki nilai kecocokan yang positif (possitive matches ). Nilai b diperoleh dari nilai vektor $i$ dan $j$ bernilai $(0,1)$ maka artinya vektor $i$ tidak memiliki kecocokan dengan vektor $i$ (absence mismatches), nilai $\mathrm{c}$ diperoleh dari dari nilai vektor $i$ dan $j$ bernilai $(1,0)$ maka artinya nilai vektor $j$ tidak memiliki kecocokan dengan vektor $i$ (absence mismatches), nilai $\mathrm{d}$ diperoleh dari dari nilai vektor $i$ dan $j$ bernilai $(0,0)$ maka artinya nilai vektor $i, j$ memiliki tidak cocok sama sekali (negative mismatches).

Rumus Socal \& Sneath II:

$$
\frac{2(a+d)}{2 a+b+c+2 d}
$$

Rumus Otsuka :

$$
\frac{a}{((a+b)(a+c))}
$$

Keterangan:

- $\quad a$ adalah jumlah dari nilai vektor $i, j$ yang memiliki nilai $(1,1)$

- $\quad \mathrm{b}$ adalah jumlah dari nilai vektor $i, j$ yang memiliki nilai $(0,1)$

- $\quad$ c adalah jumlah dari nilai vektor $i, j$ yang memiliki nilai $(1,0)$

- $\mathrm{d}$ adalah jumlah dari nilai vector $i, j$ yang memiliki nilai $(0,0)$

- 0.5 merupakan ketetapan rumus

\subsection{SKEMA SISTEM}

Istilah skema sebenarnya bukan hal yang baru bagi kita. Kata ini sudah lama milik bahasa Indonesia (merupakan kata serapan yang berasal dari bahasa Inggris 'schema'). Di dalam Kamus Besar Bahasa Indonesia (KBBI), kata skema merupakan padanan dari bagan, rangka-rangka, rancangan. Skema adalah suatu pemberian yang digeneralisasikan, suatu rencana atau struktur (Sulistyaningsih, Lilis Siti. 2016).

\subsection{SKEMA METODE SOCAL \& SNEATH II}

Skema untuk metode ini adalah sebagai berikut : 


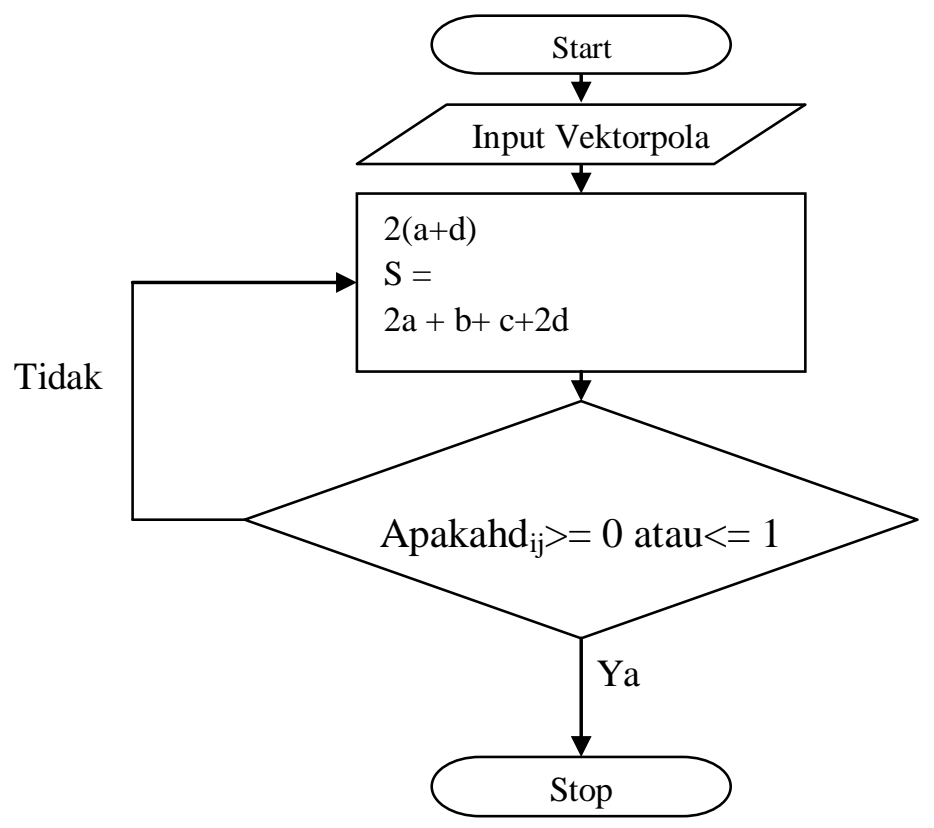

Gambar 2.1 Skema Socal \& Sneath II

Pada tahap ini, jaringan menerima inputan struktur pola. Struktur pola inputan merupakan sebarisan pola tepi-tepi objek yang mungkin mengandung setiap huruf manshub fi'il mudhari atau bukan, dan selanjutnya melakukan perhitungan matriks koreksi, dan diakhiri dengan pembaharuan matriks bobot. Langkah-langkah ini terus diulang hingga tercapat error minimum atau telah memenuhi batas iterasi maksimal.

\subsection{SKEMA METODE OTSUKA}

Skema untuk metode ini adalah sebagai berikut : 


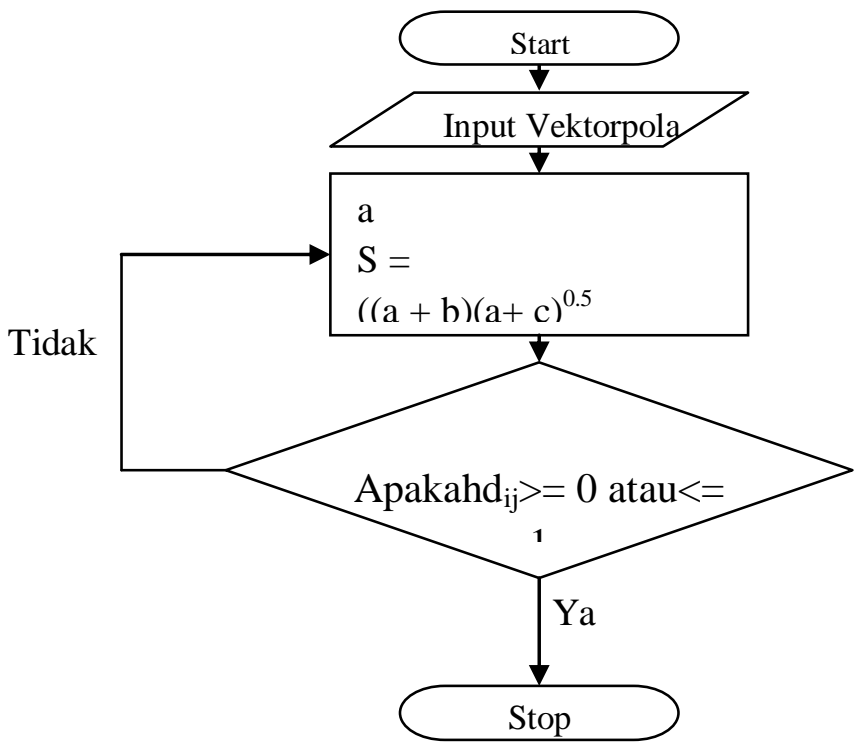

Gambar 2.2. Skema Otsuka

Pada tahap ini, jaringan menerima inputan struktur pola. Struktur pola inputan merupakan sebarisan pola tepi-tepi objek yang mungkin mengandung setiap huruf masnhub atau bukan, dan selanjutnya melakukan perhitungan matriks koreksi, dan diakhiri dengan pembaharuan matriks bobot. Langkah-langkah ini terus diulang hingga tercapat error minimum atau telah memenuhi batas iterasi maksimal.

\section{HASIL DAN PEMBAHASAN}

\subsection{PERHITUNGAN MANUAL}

Berikut adalah contoh penjabaran rumus dari metode Socal \& Sneath II untuk mengetahui jarak dua buah vektor dalam aplikasi ini adalah sebagai berikut:

Nilai sembarang untukvektoridanj adalahsebagaiberikut.

$$
\mathrm{i}=\left(\begin{array}{lllllllll}
1 & 1 & 0 & 1 & 1 & 0 & 1 & 0 & 0 \\
0 & 1 & 0 & 1 & 1 & 1 & 0 & 1 & 0 \\
1 & 0 & 1 & 1 & 1 & 0 & 0 & 0 & 1 \\
0 & 1 & 1 & 0 & 1 & 1 & 0 & 0 & 1 \\
1 & 1 & 1 & 1 & 1 & 0 & 0 & 0 & 0
\end{array}\right)
$$$$
j=\left(\begin{array}{lllllllll}
1 & 0 & 1 & 0 & 1 & 1 & 1 & 0 & 1 \\
1 & 0 & 0 & 0 & 1 & 1 & 1 & 0 & 0 \\
1 & 0 & 1 & 1 & 0 & 1 & 1 & 0 & 1 \\
1 & 0 & 0 & 0 & 1 & 1 & 0 & 1 & 0 \\
1 & 0 & 0 & 0 & 1 & 1 & 0 & 0 & 1
\end{array}\right)
$$ 
Dalam hal ini, i adalah pola nilai latih dan jpola nilai uji adalah dua vektor yang jaraknya akan dihitung, kita tentukan terlebih dahulu nilai a, b, c dan d. Adapun jarak dari Socal \& Sneath II kedua vektor tersebut berupa :

$$
\begin{array}{lll}
\mathrm{a}_{(\mathrm{i}, \mathrm{j})}=(1,1)=12 & \mathrm{~b}_{(\mathrm{i}, \mathrm{j})}=(0,1)=14 & \mathrm{c}_{(\mathrm{i}, \mathrm{j})}=(1,0)=12 \\
\mathrm{~d}_{(\mathrm{i}, \mathrm{j})}=(0,0)=10 & \\
\mathrm{~S}=\frac{2(26)}{2(12)+14+12+2(10)} & =\frac{2(26)}{2(58)}=\frac{52}{116}=0.44 &
\end{array}
$$

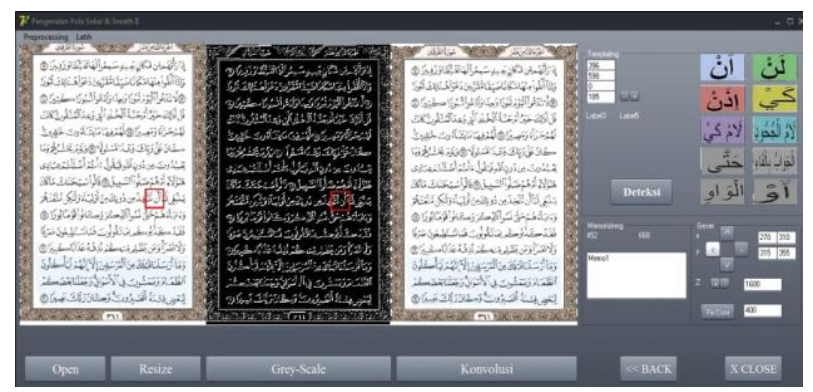

Gambar 3.1 Tampilan Sistem Pelatihan Dengan Menggunakan Metode Socal \& Sneath II

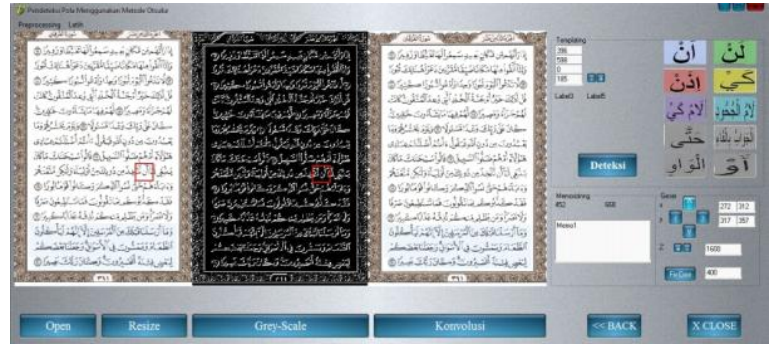

Gambar 3.2 Tampilan Sistem Pelatihan Dengan Menggunakan Metode Otsuka

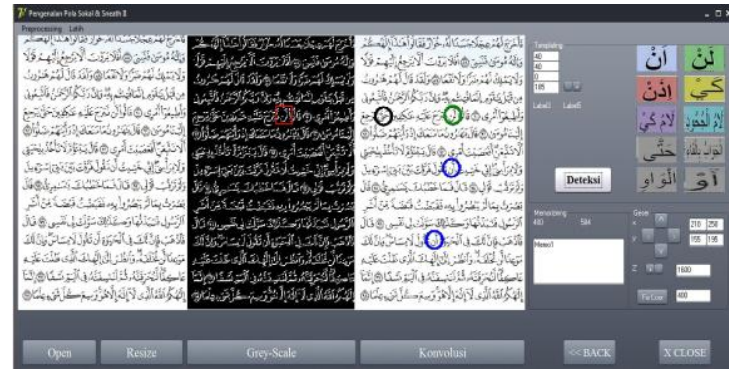

Gambar 3.3 Tampilan Sistem Pengujian Dengan Menggunakan Metode Socal \& Sneath II 


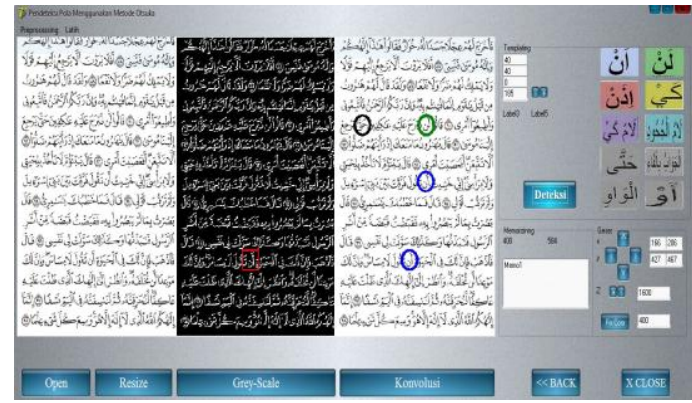

Gambar 3.4 Tampilan Sistem Pengujian Dengan Menggunakan Metode

Otsuka

\subsection{Hasil Unjuk Kerja Sistem}

Pengukuran unjuk kerja sistem ini memiliki jumlah 10 sample. pada proses pelatihan dan pengujian.

Tabel 4.6. Hasil Unjuk Kerja Metode Socal \& Sneath II

\begin{tabular}{|c|c|c|c|c|c|}
\hline No & $\begin{array}{lr}\text { Citra Pola } & \text { huruf } \\
\text { Manshub } \quad \text { Fi'il } \\
\text { Mudhari Pelatihan }\end{array}$ & $\begin{array}{l}\text { Jumlah } \\
\text { Pengujian }\end{array}$ & $\begin{array}{l}\text { Jumlah Citra Terdeteksi } \\
\text { Huruf Manshub Fi'il } \\
\text { Mudhari }\end{array}$ & $\begin{array}{l}\text { False Positive } \\
\text { Rate }\end{array}$ & Detection Rate \\
\hline 1 & & 10 & 12 & 0,1 & 0,9 \\
\hline 2 & & 10 & 2 & 0,2 & 0,8 \\
\hline 3 & & 10 & 1 & 0,3 & 0,7 \\
\hline 4 & & 10 & 1 & 0,2 & 0,8 \\
\hline 5 & & 10 & 0 & 0,0 & 0,0 \\
\hline 6 & & 10 & 1 & 0,4 & 0,6 \\
\hline 7 & & 10 & 1 & 0,5 & 0,5 \\
\hline 8 & & 10 & 0 & 0,0 & 0,0 \\
\hline 9 & الَّو او & 10 & 0 & 0,0 & 0,0 \\
\hline 10 & 91 & 10 & 0 & 0,0 & 0,0 \\
\hline
\end{tabular}

Hasil pengujian untuk, menunjukkan bahwa detection rate sangat dipengaruhi oleh sumber pola huruf manshub fi'il mudhari. karena Gambar 4.4 menunjukkan grafik hasil unjuk kerja sistem pendeteksi huruf manshub fi'il mudhari $\left(F m_{1}, \mathrm{Fm}_{2}, \mathrm{Fm}_{3}, \mathrm{Fm}_{4}, \mathrm{Fm}_{5}, \mathrm{Fm}_{6}, \mathrm{Fm}\right.$, $\left.\mathrm{Fm} 8, \mathrm{Fm} 9, \mathrm{Fm} 10\right)$. 
Keterangan:

$F m_{1}=$ Citra Al Quran yang memuat huruf Manshub 'An

$\mathrm{Fm}_{2}=$ Citra Al Quran yang memuat huruf Manshub 'Lan

$\mathrm{Fm}_{3}=$ Citra Al Quran yang memuat huruf Manshub 'Idzan

$\mathrm{Fm}_{4}=$ Citra Al Quran yang memuat huruf Manshub 'Kay

$\mathrm{Fm}_{5}=$ Citra Al Quran yang memuat huruf Manshub 'Laamu Kay

$\mathrm{Fm}_{6}=$ Citra Al Quran yang memuat huruf Manshub 'Laamu juhud

$F m 7=$ Citra Al Quran yang memuat huruf Manshub ‘ Hatta

$\mathrm{Fm}_{8}=$ Citra Al Quran yang memuat huruf Manshub 'Aljawalbu bilfa'i

$\mathrm{Fm}_{9}=$ Citra Al Quran yang memuat huruf Manshub 'Al wawi

$\mathrm{Fm}_{10}=$ Citra Al Quran yang memuat huruf Manshub 'Au

Pada Gambar 4.5, grafik mengilustrasikan pengujian dan pengukuran unjuk kerja dilakukan setelah 10 vektor pola huruf manshub fi'il mudhari dalam citra dilatih untuk keseluruhan karakteristik citra $\left(F m_{1}, F m_{2}, F m_{3}, F m_{4}, F m_{5}\right.$, $\left.F m_{6}, F m_{8}, F m_{9}, F m_{10}\right)$. Jumlah citra pengujian adalah sebanyak 10 citra $\mathrm{Al}$ Quran, untuk seluruh tahap pelatihan dan diperoleh berturut-turut nilai detection rate untuk $F m_{1}=90 \%, F m_{2}=85 \%, F m_{3}=75 \%, F m_{4}=85 \%, F m_{5}=0 \%$ , $F m_{6}=60 \%, F m_{7}=50 \%, F m_{8}=0 \%, F m_{9}=0 \%, F m_{10}=0 \%$.

Tabel 4.7. Hasil Unjuk Kerja Metode Otsuka

\begin{tabular}{|c|c|c|c|c|c|}
\hline No & $\begin{array}{ll}\text { Citra } & \text { Pola } \\
\text { huruf } & \\
\text { Manshub } & \text { Fi'il } \\
\text { Mudhari } & \\
\text { Pelatihan } & \end{array}$ & $\begin{array}{l}\text { Jumlah Citra } \\
\text { Pengujian }\end{array}$ & $\begin{array}{l}\text { Jumlah Citra } \\
\text { Terdeteksi } \\
\text { Huruf Manshub } \\
\text { Fi'il Mudhari }\end{array}$ & $\begin{array}{l}\text { False Positive } \\
\text { Rate }\end{array}$ & $\begin{array}{l}\text { Detection } \\
\text { Rate }\end{array}$ \\
\hline 1 & i & 10 & 12 & 0,1 & 0,9 \\
\hline 2 & & 10 & 2 & 0,2 & 0,8 \\
\hline 3 & & 10 & 1 & 0,3 & 0,7 \\
\hline 4 & is & 10 & 1 & 0,2 & 0,8 \\
\hline 5 & لأَخُكَ & 10 & 0 & 0,0 & 0,0 \\
\hline 6 & 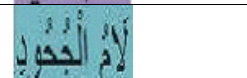 & 10 & 1 & 0,4 & 0,6 \\
\hline 7 & حَنَّتَ & 10 & 1 & 0,5 & 0,5 \\
\hline 8 & 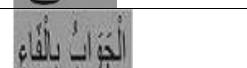 & 10 & 0 & 0,0 & 0,0 \\
\hline 9 & الّْ او & 10 & 0 & 0,0 & 0,0 \\
\hline 10 & $9 \overline{1}$ & 10 & 0 & 0,0 & 0,0 \\
\hline
\end{tabular}


Hasil pengujian untuk, menunjukkan bahwa detection rate sangat dipengaruhi oleh sumber pola huruf manshub fi'il mudhari. karena Gambar 4.4 menunjukkan grafik hasil unjuk kerja sistem pendeteksi huruf manshub fi'il mudhari $\left(F m_{1}, F_{2}, F m_{3}, F m_{4}, F m_{5}, F m_{6}, F m_{7}, F m 8, F m 9, F m 10\right)$.

Keterangan:

$F m_{1}=$ Citra Al Quran yang memuat huruf Manshub 'An

$\mathrm{Fm}_{2}=$ Citra Al Quran yang memuat huruf Manshub 'Lan

$\mathrm{Fm}_{3}=$ Citra Al Quran yang memuat huruf Manshub'Idzan

$\mathrm{Fm}_{4}=$ Citra Al Quran yang memuat huruf Manshub'Kay

$\mathrm{Fm}_{5}=$ Citra Al Quran yang memuat huruf Manshub'Laamu Kay

$\mathrm{Fm}_{6}=$ Citra Al Quran yang memuat huruf Manshub'Laamu juhud

$F m 7=$ Citra Al Quran yang memuat huruf $M a n s h u b^{\prime}$ Hatta

$\mathrm{Fm}_{8}=$ Citra Al Quran yang memuat huruf Manshub ${ }^{\prime}$ Aljawalbu bilfa'i

$\mathrm{Fm}_{9}=$ Citra Al Quran yang memuat huruf Manshub' Al wawi

$F m_{10}=$ Citra Al Quran yang memuat huruf Manshub ${ }^{\prime} \mathrm{Au}$

Pada Gambar 4.6, grafik mengilustrasikan pengujian dan pengukuran unjuk kerja dilakukan setelah 10 vektor pola huruf manshub fi'il mudhari dalam citra dilatih untuk keseluruhan karakteristik citra $\left(\mathrm{Fm}_{1}, \mathrm{Fm}_{2}, \mathrm{Fm}_{3}, \mathrm{Fm}_{4}, \mathrm{Fm}_{5}\right.$, $\left.F m_{6}, F m_{8}, F m_{9}, F m_{10}\right)$. Jumlah citra pengujian adalah sebanyak 10 citra $\mathrm{Al}$ Quran, untuk seluruh tahap pelatihan dan diperoleh berturut-turut nilai detection rate untuk $F m_{1}=85 \%, F m_{2}=70 \%, F m_{3}=65 \%, F m_{4}=75 \%, F m_{5}=0 \%$ $, F m_{6}=50 \%, F m_{7}=55 \%, F m_{8}=0 \%, F m_{9}=0 \%, F m_{10}=0 \%$.

\section{Kesimpulan}

Hasil penelitian menunjukkan bahwa sistem pendeteksi pola huruf manshub fi'il mudhari dalam Al-Quran menggunakan metode Socal \& Sneath II memiliki kisaran detection rate sebesar 90\% dan Metode Otsuka memiliki kisaran detection rate $80 \%$. Hasil pengujian untuk , , , , , , , dan , menunjukkan bahwa detection rate sangat dipengaruhi oleh nilai sensitifitas bagi masingmasing pola yang ada. Berdasarkan garfik unjuk kerja sistem pendeteksi huruf, hasil uji yang terbaik diperoleh pada yaitu pola huruf an yang memiliki tingkat keakuratan sebesar $90 \%$ dalam pendeteksiannya dengan mengunakan metode socal $\mathcal{E}$ sneath II dan pendeteksian yang mengunakan metode otsuka keakuratannya sebesar $85 \%$. Hasil uji yang rendah terdapat pada yaitu pola huruf hatta memiliki tingkat pendeteksian sebesar $50 \%$ dengan mengunakan metode socal $\mathcal{E}$ sneath II dan pendeteksian yang mengunakan metode otsuka sebesar $50 \%$.

Faktor faktor kemiripan maupun perbedaan sampel suara latih dan uji menjadi salah satu kelemahan pada sistem ini, karena sistem pengujian hafalan Al-Qur'an melalui suara memiliki nilai sensitifitas yang sangat tipis sehingga deteksi tingkat kesalahan akan muncul. 


\section{DAFTAR PUSTAKA}

Fadlisyah. 2013. Sistem Pendeteksian Wajah pada Video Menggunakan Jaringan Adaptive Linear Neuron (ADALINE). Tesis. Program Studi Magister Teknik Elektro, Universitas Seumatera Utara (USU).

Fadlisyah, S.Si. 2007. Computer Vision dan Pengolahan Citra. Yogyakarta : Andi.

Fadlisyah dan Rizal. 2011. Pemograman Computer Vision Menggunakan Delphi + Vision Lab VCL 4.0.1. Yogyakarta : Graha Ilmu.

Kadir, Abdul. 2013. Dasar Pengolahan Citra dengan DELPHI. Yogyakarta : Andi.

Nuha, Ulin M.P.di. 2013. buku lengkap kaidah-kaidah nahwu. Yogjakarta. Diva press.

Putra, Darma. 2010. Pengolahan Citra Digital. Yogyakarta : Andi.

Sulistyo, S. B. dan Masrukhi. 2011. Kajian Pendugaan Kadar Air Tanah dengan Menggunakan Pengolahan Citra Digital. Inovasi,

Seung-Seok Choi, Sung-Hyuk Cha, Charles C. 2010 Tappert A Survey of Binary Similarity and Distance Measures. Diambil dari (http://www.iiisci.org/Journal/CV\$/sci/pdfs/GS315JG.pdf, diakses pada tanggal 1 October 2017, pukul 00:24 WIB)

RD. Kusumanto dan Alan Novi Tompunu.2011 pengolahan citra digital untuk mendeteksi obyek menggunakan pengolahan warna model normalisasi RGB. Diambil dari https://www.researchgate.net//oviepoenya /jurnal-pengolahancitra.( diakses pada tanggal 25 November 2017 pukul 12.56)

Candra Noor Santi, S.Pd, M.Kom 2011 Mengubah Citra Berwarna Menjadi GrayScale dan Citra biner. Diambil dari http://www.unisbank.ac.id/ojs/index.php/fti1/article/view/346/ 223.(diakses pada tanggal 25 November 2017 pukul 13.07).

Helmy Fitriawan, Ouriz Pucu, Yohanes Baptista. 2012 identifikasi plat nomor kendaraan secara off-line berbasis pengolahan citra dan jaringan syaraf tiruan. Diambil dari http://download. portalgaruda.org/article.php?article=267901\&val=7087\&title=IDEN TIFIKASI\%20PLAT\%20NOMOR\%20KENDARAAN\%20SECARA $\% 2$ OOFF-

LINE\%20BERBASIS\%20PENGOLAHAN\%20CITRA\%20DAN\%20JA RINGAN\%20SYARAF\%20TIRUAN. (diakses pada tanggal 25 November pukul 14.15).

Max R. Kumaseh, Luther Latumakulita, Nelson Nainggolan. 2013 segmentasi citra digital ikan menggunakan metode thresholding. Diambil dari:http:/ / download.portalgaruda.org/article.php?article=107012 \&val= 1043. (diakses pada 25 November 2017 pukul 14.42) 
Fithriani Gade. 2014. Implementasi metode takrār dalam Pembelajaran menghafal al-qur'an. diambil dari http://download.portalgaruda.org / article.php?article $=267308 \& v a l=7083 \&$ title $=$ IMPLEMENTASI $\% 20$ METODE\%20TAKR\%C3\%84\%E2\%82\%ACR\%20DALAM\%20PEMB ELAJARAN\%20MENGHAFAL \%20AL-

QUR\%C3\%A2\%E2\%82\%AC\%E2\%8 4\%A2AN. (diakses pada 25 November 2017 pukul 16.00) 